\title{
Instructional Science \\ Designing for Discovery Learning of Complexity Principles of Congestion by Driving Together in the TrafficJams Simulation \\ --Manuscript Draft--
}

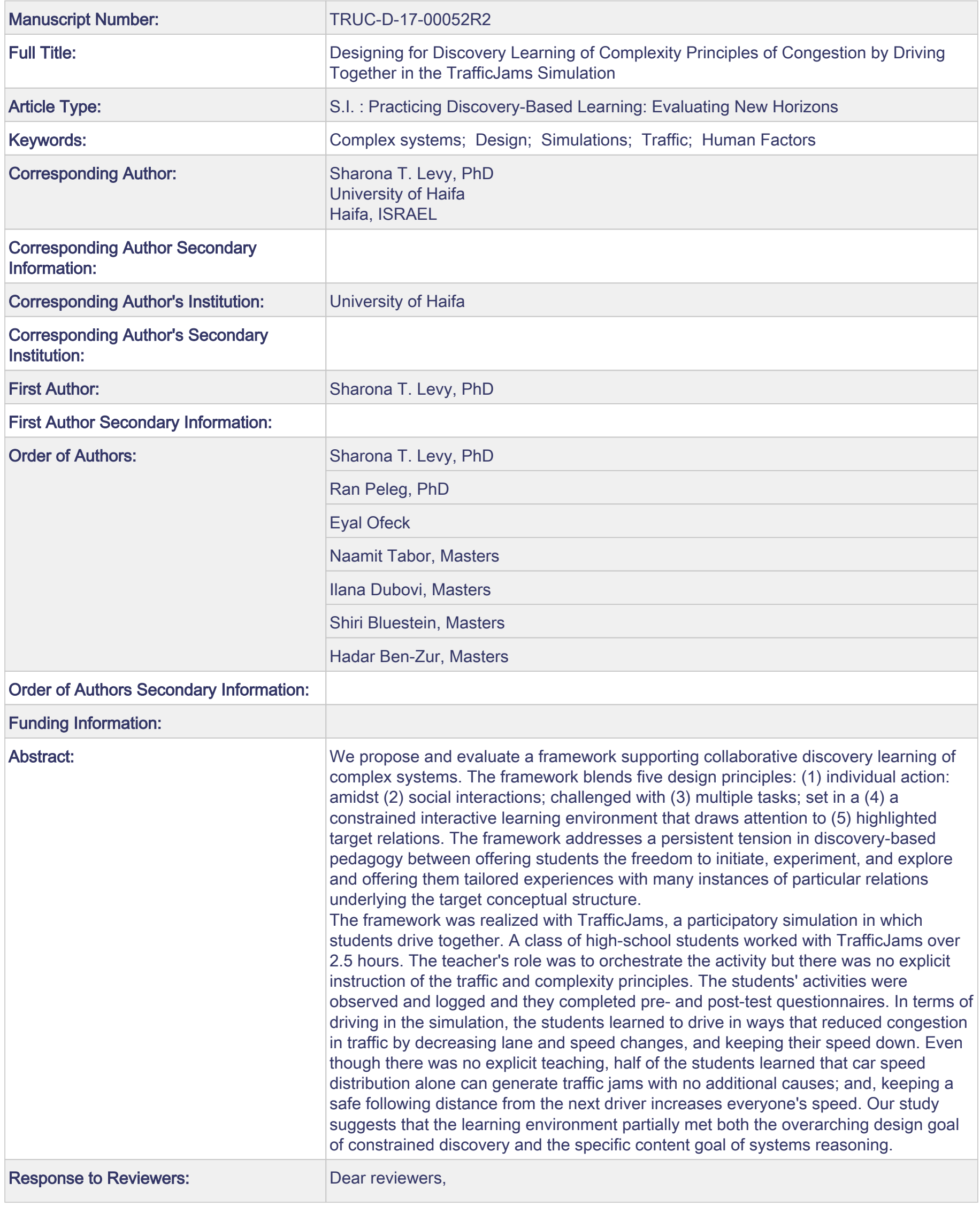


After a few rounds with the special issue editor, we have addressed many of the concerns. These are listed in the attached letter. 


\title{
Designing for Discovery Learning of Complexity Principles of Congestion by \\ Driving Together in the TrafficJams Simulation
}

\author{
Sharona T. Levy*, Ran Peleg, Eyal Ofeck, Naamit Tabor, Ilana Dubovi, Shiri Bluestein, and \\ Hadar Ben-Zur \\ Faculty of Education, University of Haifa
}

* Corresponding author: stlevy@edu.haifa.ac.il

972.4.824.0892 (telephone)

972.4.824.0911 (fax)

Faculty of Education, University of Haifa

199 Aba Khoushy Avenue, Mount Carmel, Haifa, 3498838, Israel

Submitted: Monday, December 4, 2017 
RUNNING HEAD: DISCOVERING PRINCIPLES OF TRAFFIC CONGESTION

Designing for Discovery Learning of Complexity Principles of Congestion by Driving Together in the TrafficJams Simulation 


\title{
RUNNING HEAD: DISCOVERING PRINCIPLES OF TRAFFIC CONGESTION
}

\begin{abstract}
We propose and evaluate a framework supporting collaborative discovery learning of complex systems. The framework blends five design principles: (1) individual action: amidst (2) social interactions; challenged with (3) multiple tasks; set in a (4) a constrained interactive learning environment that draws attention to (5) highlighted target relations. The framework addresses a persistent tension in discoverybased pedagogy between offering students the freedom to initiate, experiment, and explore and offering them tailored experiences with many instances of particular relations underlying the target conceptual structure.

The framework was realized with TrafficJams, a participatory simulation in which students drive together. A class of high-school students worked with TrafficJams over 2.5 hours. The teacher's role was to orchestrate the activity but there was no explicit instruction of the traffic and complexity principles. The students' activities were observed and logged and they completed pre- and post-test questionnaires. In terms of driving in the simulation, the students learned to drive in ways that reduced congestion in traffic by decreasing lane and speed changes, and keeping their speed down. Even though there was no explicit teaching, half of the students learned that car speed distribution alone can generate traffic jams with no additional causes; and, keeping a safe following distance from the next driver increases everyone's speed. Our study suggests that the learning environment partially met both the overarching design goal of constrained discovery and the specific content goal of systems reasoning.
\end{abstract}

Keywords: Complex systems; Design; Human Factors; Simulations; Traffic. 


\section{Designing for Discovery Learning of Complexity Principles of Congestion by Driving Together in the TrafficJams Simulation}

\section{Motivation and Overview}

The paper tells two nested tales. One tale is about an extensible design framework for supporting collaborative discovery learning of complex systems. The second tale is nested in the first. It relates the study of a new learning design, TrafficJams (Authors 2014), which implements the design framework. The paper is part of a suite of articles on discovery learning in the present journal issue. Within this suite, the paper uniquely focuses on two issues. One is the social aspect of discovery learning, taking place as coordinated whole-class learning activities.

Within discovery learning, external constraints combined with possible actions structure activities instead of pre-determined steps and instructions. For example, through mixing paints a child might notice that particular mixtures give the same consistent results. In this case, the paints' color-combinatorics space structures the environment and provides opportunities for experiencing the pairings of the colors combined with their mixed combination. This is distinct from being told to mix blue and yellow to get green. In this paper the paint combinatorics, or the external constraints that structure a participant's possible actions, include not only the space, materials and objects, but also the actions and interactions with other people. These actions take place in enacting the phenomena, its design and explanation. In a sense, it is not one child painting a picture, but several children painting together while sharing a large piece of paper. The painting may be an emergent form resulting from the different contributions and their interaction, so that no single child has full control of the final outcome. Through locally coordinating their efforts, an optimal result may come forth. In terms of content, the framework focuses on learning about complex systems.

One of the important capabilities we need to develop among present and future citizens is driving in congestion safely and cost-effectively. Supporting people in understanding driving as interactions in a shared space is crucial to sustained safe use of our roads (Karndacharuk, Wilson \& Dunn 2014). This research is the first of its kind to define this goal and evaluate it empirically through dedicated pedagogical intervention. The present study takes the initial step of fostering people's comprehension of traffic systems.

TrafficJams is a networked participatory simulation that was designed to enhance people's understanding of- and driving in congested traffic. In the research, we ask whether and how experiences of driving and conducting various activities together fosters a deeper understanding of how driving and traffic relate, and how congestion might be alleviated. Finally, we ask how TrafficJams might support this learning through the design principles, underscored in this framework. The goal of this paper is to study the framework underlying the design of participatory simulations - in general, and specifically in TrafficJams by attending to its five main design principles and students' related experiences and learning.

\subsection{Background and objectives of a design for collaborative learning about complex systems}

The design framework for complexity learning delineates actionable principles for building environments in which students learn about complex systems through engaging a technologically 
networked social space of the classroom that enables them to collectively represent the system under inquiry (Resnick \& Wilensky, 1998; Colella, 2000). Complex systems are made up of many entities that may act and interact among themselves. The aggregation of individual actions and local interactions emerges into its global behaviors (Bar-Yam, 2003; Vicsek, 2002). Global patterns are described in ways that are distinct from those used to describe the individuals. For example, a single sheep might approach another sheep while a flock of sheep congregates. Understanding systems presents a challenge for learners, as it requires a host of coordinations: between local and global perspectives, among individual elements, between static and dynamic qualities of the system, and between perceptions of systems in dynamic equilibrium as either static or dynamic, when seemingly stable qualities emerge out of continuous change. For example, locally an ant follows a scent to forage for food; while globally, an army of ants walks in a line. In fact, one of the more demanding coordinations involves noticing, characterizing, modeling, and integrating simultaneous processes related to several differentiated entities as they act and interact in a shared landscape. Assisting people in learning to reason about the parallel behaviors of a collection of interacting objects clearly needs a distinct set of supports, one of the main spurs for creating this framework.

We propose a design framework that supports guided discovery learning of complex systems. The framework blends five design principles:

(1) individual action: amidst

(2) social interactions; challenged with

(3) multiple tasks; set in a

(4) a constrained interactive learning environment that draws attention to

(5) highlighted target relations.

These five principles are instantiated in the design of participatory simulations, a genre of learning technologies at the heart of the present research.

This design framework can also be construed as our response to the discovery-learning versus direct-instruction controversy. As we will show, this framework removes much of the teacher's direction from the learning environment. This direction is then replaced by affordances and constraints for action embedded into the simulation wherein students navigate and explore. The framework thus explains how to create for students opportunities to explore phenomena while constraining the scope and frequency of their possible interactions. It is in this sense that we view the teacher's role as designing experiences rather than directing them.

\subsubsection{Discovery learning: addressing an enduring debate in the learning sciences}

In discovery learning, students initiate the actions that lead to independent discovery of the intended concepts (Hammer, 1997). In most examples of discovery learning, the teacher and physical or computational materials together guide the students in the process of discovery. Discovery learning supports active knowledge construction using several forms of activity: open-ended problem solving, inquiry and design-based learning (Bruner, 1961; Hmelo-Silver, Golan Duncan \& Chinn, 2007). Some of 
the research into discovery learning shows its advantages to concept learning and especially its transfer (Kapur, 2008), particularly with extended practice (Dean \& Kuhn, 2006; Brunstein, Betts \& Anderson, 2009). Several other key benefits include encouraging intrinsic motivation (Bruner, 1961), active involvement and creativity (Csikszentmihalyi, 1996), autonomy and independence, together with an adjustable pace for different learners (Lee \& Anderson, 2013). Opponents to this approach demonstrate how a caricaturized version of discovery learning that is rarely used — completely unguided discovery — is ineffective, based on theories of cognitive load and expertise (Mayer, 2004; Kirschner, Sweller \& Clark, 2006; Alfieri, Brooks, Aldrich \& Tenenbaum, 2011), particularly for inexperienced learners. They present research comparing non-guided learning and direct instruction, that shows advantages to direct instruction in a variety of domains, tasks and age-groups, including transfer tasks. In fact, regarding complex systems, the divide is even stronger, as without providing explanations in a simulations-based environment, understanding of complex systems might remain implicit, without becoming explicit (Rieber, Tzeng \& Tribble, 2004). For a comprehensive review of the controversy, the findings for both positions and possible integration, see Lee and Anderson (2013). In their review, the authors note the lack of evidence for learning from verbal instruction alone. They describe discovery learning as successive episodes of solving problems. In the process, several examples of problem solving are generated. These examples serve to ground and frame later learning, much in the way that worked examples assist in learning through certain versions of direct instruction. In the context of driving, where problems to solve are varied, at times unexpected and crucial for immediate solution, the problems are open-ended in that they usually have multiple solutions and they do not necessarily repeat in terms of their perceptual array. To drive adaptively, an understanding of the deep structure of traffic phenomena could be beneficial. This understanding could be achieved through multiple experiences of solving such problems in an open way, gradually forming examples to learn from, and bolstered by collaboration and communication or self-explanation.

\subsubsection{The Framework}

The heuristic design framework implemented in the design-research study reported herein was conceived with the purpose of addressing a persistent tension in discovery-based pedagogy between offering students the freedom to initiate, tinker, and explore, on one hand, and structuring into their learning environment many instances of particular relations underlying the target conceptual structure. We define and then combine the five design principles to describe participatory simulations as an example.

Individual Action. The framework begins with individual action. It takes a developmental approach to learning about complex systems that begins with sensorimotor interactions with the world, which gradually decenter to include local social interactions until a global view can be used and coordinated with an individual's perspective (Authors, 2008). In fact, this developmental approach speaks to learning about complex systems from the perspective of a single agent or entity, generating the system's behaviors from its local interactions that emerge into global behaviors (Chen \& Stroup, 1993; Wilensky \& Stroup, 2014). Direct experiential learning that emerges through interactions with the material world have been the hallmark of constructivist approaches to learning. The active role of the learner in constructivist 
learning (constructionism; 'learning by doing', hands-on learning, inquiry learning, discovery learning) in different content areas has intrigued educators as an important setting for learning (Perkins, 1999). These approaches base their convictions upon the importance of the individual's self-directed activity to learning.

Social Interactions. Designing for collaboration sets the activity upon a social platform, making students' experiences observable, communicable and shared. Ideas for play and experimentation can emerge and gradually coordinate in this social arena. Social learning environments are also derived from deeper-rooted views of education that regard learning as a social activity, an act of communication with oneself and with others (Vygotsky, 1978; Sfard, 2008). Learning through communication and cooperation with others has gained recognition as promoting better learning results than individual learning. Johnson and Johnson (2009) summarize decades of research showing the efficacy of cooperative learning. In terms of direct instruction approaches, one might view social interactions as detrimental, as you cannot predetermine what information students will be exposed to, and whether this information is correct. It involves considering different viewpoints and ideas, negotiation and resolution of conflicts, which could pose a cognitive load and lengthen the duration of learning. However, the benefits of collaboration to learning can also be viewed through the value of each student having many more opportunities to express their reasoning in the social space. This can also be construed as self- and other-explanations that have been found to enhance individual learning (Chi et al., 1989; Siegler, 2002; Aleven \& Koedinger, 2002). From a complex systems perspective, participants gradually come to discern other participants' actions so that their interactions can be coordinated, possibly developing a conceptualization of society as a system comprising a collective of individual entities operating and interacting in parallel.

Multiple activities. This principle opens up the scope of activity types that can be done while learning beyond the common templates of solving problems, conducting inquiry or designing. Activities can involve striving in any direction, thus offering an additional degree of freedom in choosing among activity forms or formulating the activity. Such choice includes problem solving, inquiry and design as well as added forms such as tinkering, playing around, surveying or testing the limits of the system by breaking it. This design principle supports the freedom to formulate the activity itself and shift between different forms. In terms of direct-instruction approaches, this design principle once again flies in the face of structured designs, as one cannot know in advance what choices and shifts will occur through student interaction that will in turn generate emergent forms of activities. However, placing these choices in the hands of students and the fluidity of such natural activity increase students' sense of autonomy and generativity. Moreover, opening up to various activity forms potentially increases the amount of variations on what can be changed, tested and discovered, exposing learners to many more instances of the explored phenomenon. In terms of complex systems, such multi-varied activities increase the probability that more parts of the fitness landscape ${ }^{1}$ will be explored, so that discoveries can be made.

\footnotetext{
${ }^{1}$ A fitness landscape is the range of all possible behaviors of a system structured as a function of each of its variables with respect to an outcome variable.
} 
Constrained and responsive learning environment. One way of guiding students involves designing constraints into the system, constraints that limit the range of possible actions. Limiting the number of possible actions helps students focus on particular aspects of the explored phenomenon. Providing feedback further decreases the array of information to be learned. A responsive medium delivers feedback to actions. This immediate feedback supports the creation of mappings between action and its results. Such a process supports the formation of relations and the discovery of the underlying causal structure. With respect to a complex systems viewpoint, allowing for student enactment of only simple behaviors creates opportunities to understand how a small set of simple individual rules can result in complex emergent system patterns.

Highlight target relations. This design principle relates to the previous principle of providing feedback to actions, and limits the specific pairings of possible actions and their resulting feedback. This principle ensures that the selected actions and reactions are associated through exploring the phenomenon, thus focusing learners on features of the explored phenomenon that the designer perceives as central to its understanding.

Our conjecture is that blending these five design principles opens up the range of activities one can engage with. Pairing the learning environment's responses to constrained action provides for discovery of the underlying rules, as they are echoed, amplified and evolved through social interactions. While exploratory playfulness is encouraged in such designs, discovering the underlying causal structure is promoted by limiting what can be played with and discovered.

\subsubsection{Participatory Simulations}

We approach the question of learning by discovery through investigating a specific case of the design framework, learning with a participatory simulation (hence, partSim; Resnick \& Wilensky, 1998; Colella, 2000). A partSim supports multiple open-ended collaborative activities within a responsive and constrained learning environment that highlights key pairings of action and feedback.

PartSims are networked classroom activities that immerse students in collaborative role-playing in a social-technological experiment into complex systems. In partSims, people role-play entities in a system on a social platform. The interactions between participants' actions and other objects in the simulation within the constraints built into the simulation result in the system's overall behavior. These experiences as individuals, and as a collective - become an object of question, manipulation, and discussion, transforming the classroom itself into the explored system. The teacher's role is central in designing the activity, connecting it with other learning taking place, eliciting students' descriptions of experiences and their ideas, supporting conversations that involve local and global perspectives of the simulation that took place, and helping students concretize experiments they would like to conduct.

As a design for learning, students experience the system as its entities, orchestrators, and explorers. They are each an individual agentic entity acting and interacting locally. The class itself is the investigated system made up of many such entities, where students orchestrate experiments. Through these experiments, they explore emergent processes. The unique aspects of learning with such a design lies in 
traversing between these three perspectives, which provides for a more robust conceptual understanding of the system. Several simulations of this type have been developed over the years, approaching a wide range of topics: epidemics, evolution, bee-hives, global warming, structure of matter, traffic, topics in probability and statistics, functions, geometry, sharing resources, economic markets and more.

Classroom research into learning with partSims is quite sparse. Colella (2000) explored how highschool biology students used Thinking Tags to learn about the spread of disease. During three weeks, the students conducted several investigations. These investigations began with the challenge of meeting as many people as possible without getting sick. There were no public displays in this study, and students accessed global data only at critical points to confirm their hypotheses. Several aspects of the simulation were explored: students' engagement as seen in their excitement and sense of truly experiencing the simulation; the process that took place as the students stepped back to figure out confusing situations; the students' design of several experiments varying their behaviors to find out about the dynamics of the system; the inclusive nature of these activities as the students were all interdependent in conducting their experiments; and how experimental design of investigations into the structure of the system happened only in the later simulations. Ares, Stroup, and Schademan (2009) analyzed high-school students' discussions and learning of mathematics by having them each control an elevator among a series of elevators in a HubNet simulation. During the lesson, students were highly active both in participating in the activity and in contributions to the class conversation. These discussions primarily involved observing and describing the simulation, but also predicting, asking for clarification and explaining. The teacher's role was creating very open invitations: invitations to predict, but also to elaborate and explain. Klopfer, Yoon, and Perry (2005) explored teachers' perceptions of partSims and found that they saw affordances regarding motivation, engagement and self-directed learning. Stroup and Wilensky (2014) describe sixth-grade and high-school students' reasoning about epidemics and traffic flow in the context of partSims. They found complementarity between two forms of reasoning: the agent-based account of the system, that begins with individuals and builds up; and the aggregate collective account that is framed in terms of populations, rates and flows (see also Wilensky \& Abrahamson, 2006). These designs have been extended even to young elementary school students using mixed reality in research in which participants' movement in real space are captured and incorporated into a collaborative partSim about matter, showing conceptual learning of the topic of phases (Enyedy et al., 2015).

\subsection{Discovering Principles of Congestion by Driving in Traffic Jams}

The above-described framework was realized with TrafficJams, a participatory role-playing simulation in which students drive together on a virtual road (Authors, 2014). The simulation enables both an egocentric and global view of traffic. The activities are designed to highlight central features and encourage students' explanations and communication regarding the phenomena they encounter.

In the 1990s, a new physical concept was introduced into research on traffic flow (Nagel \& Schreckenberg, 1992; Kerner \& Konhäuser, 1993; Bando et al., 1995), viewing it as a dynamical phenomenon in a multi-agent system, or a complex system. Such a system drastically changes its 
macroscopic (system-wide) properties due to the effect of the collective motion of interacting elements at the micro-level. In this paper, we claim that understanding how individual behaviors of drivers interact and form emergent patterns of congested traffic flow has become of central importance. This results from two main problems - the high mortality of drivers and their passengers from crashes while driving in traffic and traffic congestion as a way of life we need to adapt to.

Over 33,000 people die every year in traffic accidents in the US (Fatality Analysis Reporting System, 2017) at a rate ranging 10-15 deaths per 100,000, the most frequent non-disease cause of death. 1.25 million people worldwide die each year as a result of road traffic crashes (WHO, 2015). In Israel, this rate is 300 deaths per year. Traffic accidents result from several causes that are related to road infrastructure, vehicle condition, external conditions and human factors. Human factors have been found to be the main source of car accidents (Evans, 1996; Petridou \& Moustaki, 2000; Wagenaar \& Reason, 1990; Verschuur \& Hurst, 2008) and are the focus of this study. Some causes in the human factors group may be related to drivers' misunderstanding of traffic (Kerner, 2004), particularly how their own driving might impact traffic; however, this has not been tested in research. Several strategies are employed to reduce accidents, such as improving the infrastructure and increasing surveillance and sanctions. This project complements such measures by supporting change in drivers' behavior through extending their local view to a basic understanding of the complexity of the traffic system.

Several driving behaviors contribute to traffic accidents, such as increased speeds, getting too close to the car in front and lane changes. Some surprising behaviors include the tendency to pass a car even when it's faster (Bar-Gera \& Shinar, 2005). While people are aware of how such behaviors decrease their safety, there is a significant gap between people's perception of themselves as safe drivers and their actual behaviors. Many people report that they perceive themselves as safe drivers, yet these same people also report on behaviors such as keeping too close a distance from the car in front in a congested area, driving significantly over the speed limit or not providing the right of way to pedestrians (The National Road Safety Authority 2008). Even though many drivers perceive their own driving as safe, they also perceive the main cause of accidents as other people's unsafe driving (Sikron, Baron-Epel and Linn 2008), highlighting the gap between general perception and self-perception of safe driving. Several factors contribute to aggressive driving behaviors, such as the drivers' gender and age, the presence of passengers (Shinar and Compton 2004). Addressing this gap by using simulations and discussion may help people become more reflective regarding their own driving.

Traffic congestion is a condition in traffic systems, in which their increased use results in slower speeds, longer driving times and increased queuing. It is fast becoming a steady experience of city life, a part of our fabric we need to adapt to. An ambitious recent study of congestion in 38 countries and more than a thousand cities has found that commuting drivers spent an average of $9 \%$ of their driving time in congestion; and, that in the ten most congested cities a driver might spend on the average 59-104 hours a year sitting in traffic jams (Cookson \& Pishue, 2017). In Europe, for example, the cost of congestion in commuting times, pollution and other factors is estimated as equivalent to $1 \%$ of the GDP, or 110 billion 
Euros a year (Christidis \& Rivas, 2012). Several traffic management systems have been developed, such as traffic reporting, navigation systems, and advisory message signs. In this project, we shift the perspective from how the environment can assist the driver to how the driver can assist her- or himself and their surroundings in managing traffic.

Traffic flow can be typified by three phases (Three phase traffic theory; Kerner, 2004): free flow, synchronized flow (heavy but steady), and wide moving jams (congestion). Beyond a critical vehicle density, the state of flow changes from free flow to synchronized (breakdown phenomenon), or from synchronized to unstable (pinch effect). In the project, we provide experiences of synchronized flow. When participants avoid sources of turbulence in the system, the collective cars' average speed rises, possibly reaching a coordinated phase of traffic (dense and fast), the sweet spot for driving in congestion. In order for heavy traffic to exhibit this pattern, several driving behaviors are needed on the part of drivers: greater headway between cars, limited speed, merging in particular patterns, reducing braking to a minimum, and reduced lane change. This is the connection we wish to make, as these very same behaviors not only reduce congestion but also increase drivers' safety, possibly reducing crashes. By helping drivers develop a systemic understanding of the dynamics of congested traffic, we wish to change their concepts of how specific driving behaviors that happen to be safe lead to better traffic flow and shorter commute times.

Traffic is a complex phenomenon with surprising emergent properties. Central concepts about traffic are highly counter-intuitive and even paradoxical when comparing patterns at the micro- and macrolevels. For example, while cars move forward, traffic jams move backwards (Wilensky \& Resnick, 1999); "slow is fast" - driving slower while keeping headway (distance between cars) and avoiding lane changes results in faster traffic. These surprises may be at the root of disruptive driving behaviors. By helping people understand these concepts, their more realistic expectations could translate to better traffic flow as in fact, safe driving is a self-interested behavior.

One could anticipate the rise of such misperceptions. People's access to global traffic information is limited and there are more general challenges in understanding complex-systems.

When driving in traffic, we are constrained to a local view of traffic, spanning a few cars in each direction, depending on the terrain. We usually lack a global view of the flowing, jamming, splitting and merging of traffic, even when using driving navigation applications.

More general difficulties lie in making sense of systems, such as confusing between micro- and macro-levels and assuming centralized causes for changes in the system (Resnick \& Wilensky, 1993; Wilensky \& Resnick, 1999), shifting from static to dynamic views of a system (Hmelo-Silver \& Pfeffer, 2004) and having difficulty in considering the stochastic character of properties and events in the system (Jacobson, 2001). Understanding phenomena that show dissimilar behaviors at the micro- and macrolevels, as in the case of traffic, are more difficult to understand (Authors, 2017). In Table 1, we relate such general complexity ideas with traffic concepts.

- . - . - -

Insert Table 1 about here 


\subsection{The Design of the TrafficJams Participatory Simulation}

The first step in design was an analysis of traffic, its paradoxes and misunderstandings by drivers (Kerner, 2004). From these misunderstandings, a sub-set that is more crucial in mismanagement of congestion, was selected and translated into learning goals: making such paradoxes apparent in the system's responses to participants' actions, and supporting the enactment of a wide range of activities. In the TrafficJams participatory simulation (Authors, 2014), people drive together on a common highway and gain the less familiar helicopter's perspective of traffic flow. They drive on a two-lane road (environmental constraints). At the individual level, they can accelerate and decelerate and move between two lanes, or off the highway (constrained actions). They experience their individual constraints (slowing down to avoid a crash) and possibilities (moving into a neighboring lane that is relatively open) as well as their individual speed as it relates to how fast they can move forward. At the group level, participants can determine whether the simulations should include trucks, have accidents, and plan and conduct collaborative experiments regarding individual behaviors, such as having everybody drive at the same speed. The average speed of the cars is displayed in a plot, allowing comparison between earlier and later driving within a single experiment, as well as between successive experiments. In the process, they may discover the relationships between driving and traffic. TrafficJams was created with NetLogo HubNet (Wilensky \& Stroup, 1999; Wilensky, 1999), and is based on the Traffic model (Wilensky, 1997).

In TrafficJams (Figures 1 and 2), participants drive cars (right hand interface) and decide whether to shift lanes or slow down. However, the computer simulation sets up the roads which constrain the motion and provides collective information, such as the average speed (left hand interface). For example, in the average speed plot, one can see the speed first oscillate and then take a downward dip as a traffic jam forms. On the students' computer, they can see the cars around them but not beyond. They can speed up or slow down and shift lanes, or merge, limited by the cars up ahead and the road itself. As a group, they can observe the teacher's computer that provides a birds'-eye view of the road, and notice how the traffic jams - local high density of cars - gradually spread through the system. They can design experiments aimed at smoothing the traffic flow or speeding it up, using a variety of strategies, such as limiting the speed or the distance between cars. Our assumption in the design is that this distribution of computation between a group of people and the simulation provides for enough constraints from the computer so that the conceptual structure of relationships in the system is retained; it can then be explored and discovered through people's actions, communications and collaborations.

In designing learning environments, we cannot always predict what the maximal exploratory freedom could be, given constraints such as duration and the very fact that students are learning a topic that has not been learned before. As a result, one of the initial processes involves opening the activity to maximal freedom, researching it, and based on this, creating additional features or structures. The present study exemplifies this first stage of the design.

The goal of this paper is to study the framework underlying the design of participatory simulations 
- in general, and specifically in TrafficJams - by attending to its five main design principles and students' resultant learning. The following research questions drive this study:

RQ1: To what degree does a minimally guided simulation of driving collaboratively support learning about congestion and driving? What concepts related to traffic congestion and the relevant complexity principles were learned by high-school students through social role-playing in minimallyguided activities with a collaborative driving participatory simulation?

RQ2: How, if at all, do the five principles in the framework - individual action: social interactions; multiple tasks; a constrained interactive learning environment; highlighted target relations - play out in supporting learning within these activities?

\section{Method}

The study described in the paper was conducted as part of coursework in the first author's graduate course on learning about complex systems. The idea of carrying out the study came up during the semester, and the short time span framed some of the methodological decisions. The study itself was a preliminary design experiment in its first iteration, meant to understand and later extend the design itself, while illuminating how the process of learning takes place and what may be emergent learning outcomes. It involved forming the class activities and the last stages of the simulation, and the data collection tools. In terms of research design, it was planned as a pretest-intervention-posttest study.

\subsection{Participants}

Twenty-nine high-school students participated in the study. Due to a network failure, the post-tests were lost. Following our request, 16 completed the post-tests at home; thus, only they are included in the analysis. Participants include seven girls and nine boys aged $M=16.6, S D=.5$ years. The school is a rural high-school in the north of Israel. Nine students did not have a driving license, four were in the process of learning to drive and three already possessed a driving license: two for a tractor and one for a motorcycle. Sample selection was opportunistic, selected as an organic high-school classroom that had a "driving safety" lesson on the day of the research. We worked with an eleventh-grade class that had a "driving safety" lesson that day, which the principal agreed to extend to a double period.

\subsection{Procedure}

A class of high-school students worked with TrafficJams during two-and-a-half hours as part of their Traffic Education course (Ministry of Education, Road Safety Branch, 2017). They completed preand post-test questionnaires. Students' identities were converted into codes from the start to avoid identification. The activities were observed by four of the authors. The lesson itself is described in detail in the findings.

\subsection{Data Collection Tools}

Two questionnaires were used for assessment. The same questionnaires were administered preand post-intervention.

The first questionnaire is a part of the "self-aggressive driving" questionnaire that was developed by Sikron, Baron-Epel and Linn (2007). Five items were selected from the original questionnaire. These 
items asked participants to mark how many times they had displayed several driving behaviors such as slowing down to prevent an accident, driving on the left lane not in order to pass a car, or cutting in front of a car in a way that makes it slow down. Unfortunately, results from the "self-aggressive driving questionnaire" were lost due to network failure, only five responses were recovered, and so the data is not reported on.

The second assessment, the "understanding traffic" questionnaire, was developed in-house. It included a movie of congested traffic using a wide view at a large interchange in which several local events of interest could be observed (Mzaviation, 2011; https://www.youtube.com/watch?v=ii6tJVdln1o). Two open items asked students to describe and explain the scenario, with a focus on how traffic jams are formed: Describe what you have seen in the movie in detail; In your view, explain why the events you described happened (how does a traffic jam form).

Students' actions in each of four simulation runs were logged, including time in ticks (model time), identity numbers, location, direction, speed, acceleration, lane change and more.

Finally, an activity protocol and observation protocol were created. The activity protocol included the various stages of the lesson, suggested activities and possible topics for discussion. The observation protocol was based on the Falk and Storksdieck (2005) contextual framework for learning in free-choice learning environments, such as science exhibitions. It included several aspects of the personal context (e.g. reference to personal experiences as drivers or riders), the socio-cultural context (e.g. interpersonal communications among students or with the teacher) and the physical context (references to the simulation architecture or design).

\subsection{Data Analysis}

Analysis included three parts.

To obtain a summary perspective of the class activity, the activity logs were analyzed to provide information that connects individual behaviors and global patterns. The unit of analysis is an individual driver, and results are aggregated for the group that included $\mathrm{N}=18$. Two individual driving behaviors were averaged for the participants in each simulation run: lane changes and speed changes. Global traffic outcomes included each of the run's durations, the group's speed, and the average number of laps completed by each of the cars in the simulation.

Five class observations were made, collected and compared in order to test for agreement regarding several of the events and issues. These were then used to create the story-line of the activities in terms of idea generation, goals, and process; typifying behaviors within the learning environment and portraying the learning of traffic and systems principles.

Students' "understanding traffic" pre- and post-test questionnaires were first open-coded and compared until we could surmise regarding dimensions of variation among participants and from the pre- to the post-test: whether or not traffic jams were attributed to centralized causes, whether single or many causes for congestion were described, whether car speed distribution is noticed and used in reasoning about congestion, whether reasoning could be typified as top-down or bottom-up and finally, whether or not 
mechanistic or direct causal explanations are employed. We then coded the students' questionnaires and noted the changes from pretest to posttest along the different dimensions. Statistics were not used due to the small sample size.

\subsection{Trustworthiness}

Trustworthiness (Lincoln \& Guba, 1985) is the qualitative researcher's toolbox for increasing rigor and transparency, and thus, the integrity of the findings. Trustworthiness was established in two ways. Credibility, confidence that the findings are true and accurate, was established with the use of triangulation. Four of the authors independently wrote out their observations in a pre-established format. These writings were compared and aligned to ensure the repeating themes were attended to. Confirmability, or the degree of neutrality in the reported findings, was ensured by basing the analysis on actual texts the study's participants produced and their transcribed articulations.

\section{Findings}

Findings are presented in the following order. The actual driving behaviors and traffic patterns, based on the log data analysis, are first presented for each of the descriptors. We then turn to a more qualitative description of the activity, interspersing it with the quantitative features related to each of the four simulation runs, to increase the richness of the data and triangulate some of the findings. Finally, we analyze the questionnaires, noting concepts that did not and did change following the activity.

\subsection{Driving Behaviors and Traffic Patterns}

The activity logs were analyzed to gain a global perspective of what happened in each of the simulation runs. Driving behaviors and traffic outcomes are described in Table 2 and Figure 3.

\section{Insert Table 2 about here \\ - - - - - - \\ - . - . - - \\ Insert Figure 3 about here}

In comparing the features of traffic during the four runs, we see the following.

The first run was much longer than the others. In fact, the trend is that the runs get shorter with successive runs, possibly reflecting: students' need to initially explore the available tools; more efficient use of the tools at hand; better self-organization in applying the agreed-upon strategies; greater interest in just exploring the system in the first run; or possibly, boredom.

The average speed changed dramatically between runs. It reduced extremely on the second run when the students were developing their best traffic jamming strategies. Contrary to that, the average speed increased by $50 \%$ in the last run, when they applied their best strategies for keeping traffic going smoothly and quickly. In these cases, we can see a connection between the goals and whether they succeeded. The maximum speed is due to the fastest drivers. It is interesting to see that only in the fourth run, does this 
maximum speed reduced significantly, showing the greater compliance of the speediest drivers. The fact that the minimum speed is zero for all runs shows us that cars were stopped up at some point regardless of the other features describing the simulation run.

The average number of laps completed by the cars is diverse in the various runs and its distribution among drivers changes as well. This dimension is not directly related to the average speed as one might expect. Traffic could get jammed up (driving at slower speeds) but the participants could persevere, and still keep going at the simulation for an extended time, so that they eventually covered these distances.

Individual driving behaviors are compared.

The students sped up and slowed down (accelerated) to a similar extent in the first two runs, increasing in rate during the third run. In the four run, such changes in speed were reduced extremely.

Lane changes were noted for each student for each run and averaged. In the first run, there were relatively few lane changes, possibly reflecting a combination of the participants not yet gaining full control of the car, as shifting between lanes is more difficult to control - one needs to notice whether there is a gap in traffic next to them or coming up, and move into that gap at the right moment. The third run shows a large increase in lane changes.

Each of the simulation runs is described in the next section together with the class observations.

\subsection{The TrafficJams Activity}

The lesson took place in the computer lab; each student sat at a computer. One of the authors took on the role of the teacher. The class's driving safety teacher remained in the classroom, observed and took notes that were later discussed.

In order to start the students wondering and possibly eager to explore, two movies were first presented pertaining to one traffic phenomenon, phantom traffic jams - the persistence of traffic jams long after their cause has been eliminated. The phenomenon was not explained and the movies served to help students notice surprising properties of traffic. A one-minute excerpt from the movie Mission Impossible III (Cruise, Wagner, Haicheng \& Abrams, 2006; https://www.youtube.com/watch?v=v51Z6NMf8S0\&feature=youtu.be) was viewed, one in which the main actor describes his view of traffic as a living organism and talks about phantom traffic jams Then a second 2.5-minute movie was viewed - a documentary about phantom traffic jams from an engineer's perspective (excerpt from Silverfox, 2009; https://www.youtube.com/watch?v=UQuBzCNmazo).

The activity was then introduced to the class through a short explanation and a worksheet that showed them how to enter the simulation and use the interface to accelerate, decelerate and shift lanes. They were then asked to find themselves on their own screen and on the class screen.

\subsubsection{Simulation Run 1.}

The first simulation run involved students' free-form driving to gain experience operating their virtual car. It is also accompanied by some cheerful bedlam as students are typically roused and delighted by acting through their own computer and seeing their avatar with other students' avatars on the public 
display screen. Some of the students needed assistance in learning to use their interface. After finding their car in the simulation, much of the interactions among students involved asking for advice on how to use the tools "How do you reverse?" and finding out who each of them was "Who's number one?". Their focus was on local interactions, especially on the drivers of the cars just ahead of them, e.g.: "They're blocking me. Who's number one? Ooof, mine isn't working. \&\$**\#"'. During this first simulation run, several of these comments also showed that the students had bought into the simulation: "I reached $200 \mathrm{kmh}$ !"; "Ten and Five, get out of my way"; "Who's the ant?"; "Seven - get out of the car if you dare!"; "I can’t drive, there's traffic in the right lane."; "Fourteen, you drive like my grandmother." They spent twenty minutes figuring out the constraints - what they could and could not do. For example, accelerating while there is a car right in front results in an accident and eventually brings the traffic in that lane to a complete standstill. Finding out what is happening in the simulation is taking place in small local conversations among the students, such as: "Why is everything red?" - "Because you ran into the car in front of you". This first stage is necessary as students need to get used to operating their "body" after it is moved to a virtual space. They also need to notice what reactions in the world result from their actions - both physically and in terms of interactions with the other drivers. In past experiences, we have found that it is an important prologue to more reflective classroom activities later on.

Based on the logging data, driving behaviors show a smaller number of both speed and lane changes. Thus, even though they were trying to jam traffic, the average speed of driving was middling their abilities and goals not yet aligned. As in actual driving, lane changes require greater dexterity of the driver. Changing lanes in the simulation requires making sure there is a space in the target lane and moving into it at the exact right time. As a result, we see much fewer lane changes in the early run. The run was much longer than the others and more laps were completed by each car, reflecting the greater needs for free exploration of their bodies and environment. This exploratory spirit aligns with the functional and playful conversations described above. It is also related to the still-developing control students had of the tools they used to navigate and in the environment.

\subsubsection{Simulation Runs 2 and 3.}

In later simulation runs, students move their attention beyond their own actions and interactions to relating global patterns to individual coordinated behaviors. Most of the conversations are now directed more broadly to the class, not only locally to their neighbors (in class or in the simulation). They use the language of driving to discuss the simulation, e.g. "Let's all get to one area, and then we'll all drive at ten kmh", "We should drive as fast as possible and then there will be collisions and a traffic jam."; "It's stuck. Because they decided that we're driving faster, we all got stuck." Regarding the latter quote, the student was complaining about other students who were not complying with the class' strategies and were driving very fast. These speedy students who up in the log analysis as capping the maximum speed. This maximum speed went down with time, as compliance increased. It also reflects how the students relate to the group interactions and efforts to engineer a complex phenomenon in a more nuanced way. Within these more system-wide references, individual interactions are still noticed: "Why did you pass me driving more than 
$80 \mathrm{kmh}$ ?"; or "The truck is annoying, it's driving at legal speed." At this point, they are attending both global features and collective strategies - and local individual interactions.

After the initial exploration stage, the teacher presented the first challenge to the students: "Make traffic jam", a very clear goal. Using such a playful approach sets the tone for student-initiated expression. We had prepared some activities but withheld them, as the participants had abundant designs of their own. Students proposed three strategies for increasing congestion. These activities were listed on the board and discussed. The class then voted which ones they wanted to try out and two were enacted: (a) each participant drives in the right lane, close together, thus increasing the density of cars; and (b) each driver makes frequent lane changes, thus increasing the friction within the flow. In the first simulations, they had chosen to include accidents, which resulted in much gore (red splatters) and joy. Later on, they removed the accidents so they could run the simulations more smoothly. The simulations themselves were led by the students, who came up with the ideas, and were assisted by the researchers to help clarify how the ideas were translated into the actual behaviors in the simulation. The students were first surprised by this setup and shy in participating, but were quick to adapt. Each simulation run was followed by a class-wide discussion, when students described their experiences as individuals and their views of the resulting traffic system. In this process, they pointed out how different driving behaviors could result in congestion. It is important to notice that while the teacher facilitated this conversation and others, she did not introduce new traffic or complexity concepts. She drew upon their contributions and invited elaboration and explanation, as well as alternative views. During this phase, we could hear students comment on various aspects of the simulation: their personal identification with their avatar (four events, e.g. "I'm the cute turtle"); pleasure (five events, e.g. "It's a real computer game!"); frustration (six events, e.g. "Enough! People are colliding with me all the time!"); and interactions (21 events, e.g. "Ten, could you move already?”).

The social aspect of these activities can be seen in three types of exchanges: during the simulation between students who are near each other as in the examples above, while planning the next simulation and when making sense of the previous simulation outcomes. In the next section a planning conversation and a summary conversation that reflects upon the recent simulation run are described.

Based on the logging data, the second run had a smaller number of speed changes than the first run, but included many more lane changes, showing that the controls were used more easily as the students' dexterity in using the tools increased. This run was the slowest of all by far. This had also been the students' goal so we can see a good alignment between the student' expressed goal and the resulting traffic patterns.

The third run is curious. It is the shortest run of the four and has a middling speed. The rate of speed and lane changes among students is the highest among the runs. At this point, the students' explicit goals are aligned with the simulation's results, but the degree of success of this experiment in making traffic jam is lower than that of the previous run. In exploring the outcomes of these different strategies, students may be making stronger associations between driving behaviors, strategies and traffic patterns - as we will see in the next and last simulation run. 


\subsubsection{Simulation Run 4.}

At the next step, the teacher set the next challenge: "How can we make traffic move faster?" At this point, the average speed graph on the main simulation window was pointed to and gradually became part of the class discussion (Figure 2). As before, students' ideas were expressed and put up on the board, then voted on. In the following excerpt, we can listen to students plan and discuss possible strategies to experiment with. After the teacher's challenge, several students are speaking. Students listen to each other and either support the ideas or suggest alternate ones. Student 15 proposed: Let's all increase our speeds at the same time and at the same rate." Student 4 countered with: "Let's split between the lanes." Another student suggested: "Let's all drive at $80 \mathrm{kmh}$ ", at which point several students called out "Yes, let's do that one!". The class took up this last idea. The students then designed two experiments: (c) having everybody drive at the same speed of $80 \mathrm{kmh}$, and (d) having all cars drive spaced out in one lane to prevent cars from cutting in and slowing traffic. Across the runs of the simulation, the average speed graphs were overlaid so they could be compared. Using this metric, the students could observe how the cars' speed increased from one run of the simulation to the next; and how within a run, the temporal pattern shows how the traffic system eventually collapses as seen in the reduction in average speed once coordination was lost. In the conversation following the simulation run, we hear the students discussing and reflecting on their experience, noting both local interactions and global properties of the system. During the steady low speed activity, some of the students complied with the class strategy, but others did not - Student 16 drove at 100 $\mathrm{kmh}$ and Student 15 drove at $70 \mathrm{kmh}$. In the conversation following the run, Student 15 asked Student 16 "Why did you pass me, driving more than $80 \mathrm{kmh}$ ?" and was answered "Because I was bored". Student 15 then summarizes pleased: "Excellent, this attempt went rather smoothly, in comparison to the previous runs."

In several conversations taking place throughout the activity, students reported on their own experiences, concepts and emotional states while driving together. The individual students' driving behaviors were diverse, varying in timidity (keeping to the right lane, keeping headway), and whether or not the class strategies were adhered to. Discussions included how an individual driver could impact the collective traffic and vice versa. Students discussed their frustrations when not being "first" in a queue of cars and how it caused them to be less willing to cooperate with the class strategies. In the fourth run where they were to all drive at $80 \mathrm{kmh}$, a small number of students drove much faster. However, by then the traffic system itself was very stable. The students had in fact reached the synchronized phase of traffic, when cars are close together yet still moving fast, or the ideal sweet spot for handling congested traffic. As a result, the noncompliance of the fast drivers was not even noticed, and was discovered only through the class discussion.

In the fourth and last simulation run, the group achieves a partial compliance of the speedy drivers, and the maximum individual speed (the non-compliant behaviors) reduces enormously, though not to the requested $80 \mathrm{kmh}$. Relatedly, the cars' average speed shoots up. At the individual level, while the number of lane changes is slightly less than the previous run, the number of speed changes has reduced 
dramatically. This reduction in speed changes results from a combination of the smoother traffic, so that one need not slow down that much, or a conscious effort of each of the drivers to keep to a certain agreedupon speed.

The last conversation was concluded by one of the students: "The point is that the same behavior of keeping your distance both accelerates traffic and prevents accidents." Another student reflected: "I think the simulation made it clear to me that congestion is an important parameter in traffic, but the way people drive - whether you're considerate or self-centered - is the parameter that most impacts whether traffic is comfortable or not."

\subsection{Conceptual Understanding of Traffic and Systems}

In the pretest and posttest "understanding traffic" questionnaire, the students were shown a movie of heavy traffic on high-ways with an interchange, and asked to described and explain what is happening in the movie. Their answers were coded for the following dimensions: using a decentralized view of traffic jams, understanding that multiple causes could create traffic jams, viewing cars' speed as distributed and this distribution generating jams, viewing cars as varying their speeds and this variation generating jams, reasoning about traffic bottom-up or top-down and reasoning about traffic jams mechanistically (Table 3).

- . - . - -

Insert Table 3 about here

In Table 4, the shifts from pretest to posttest are presented. About half of the students $(9 / 16)$ advanced in their understanding of traffic for -at least one dimension, mainly regarding uniquely complexsystems related issues of decentralization (4), distributions that generate traffic jams - of speeds (4) and of causes (3). We see a shift from a global centralized view "I think the jam is caused from merging a number of lanes ..." to an emergent-decentralized view of cars repeatedly raising and lowering their speeds, a precursor for understanding that congested traffic is a wave. "Cars slow down and speed up during a traffic jam. I think this happens because not all the drivers drive at the same speed and that causes everybody to slow down, which causes the jam." Noticing this distribution of speeds marks some of the students' learning "every driver drives at a different speed"; "not all the drivers drive at the same speed". We also note that smaller numbers of students' answers in the posttest showed an understanding of traffic as a wave ("because the cars slow down and speed up"), different sources of congestion such as cars cutting into traffic ("cars trying to pass each other"), and the importance of having cars avoid tailgating ("keep enough distance"). We have also seen regression with respect to these ideas, with two students shifting from mechanistic to non-mechanistic reasoning, one of them focusing on single causes for traffic-jams at the end, but not at the beginning. 


\section{RUNNING HEAD: DISCOVERING PRINCIPLES OF TRAFFIC CONGESTION}

\section{Discussion}

We have proposed a design framework that supports guided discovery learning of complex systems. The framework blends five design principles centered on individual action: (1) individual action: amidst (2) social interactions; challenged with (3) multiple tasks; set in a (4) a constrained interactive learning environment that draws attention to (5) highlighted target relations. With respect to this issue's common theme that revisits the question of discovery learning, we attend to the teacher's direction in this type of learning activity.

This framework was implemented as a participatory simulation, TrafficJams, and a design experiment with a class of high school students was conducted. We asked whether this design fosters a deeper understanding of concepts related to how driving and traffic relate, and how congestion might be alleviated. This question is discussed through the perspective of traffic and complexity concepts, and then through the perspective of the framework's main design principles.

\subsection{RQ1: Discovering Principles of Congestion by Driving in Traffic Jams}

TrafficJams is a collaborative participatory simulation. This genre of learning activities provides students with an arena to conduct a wide range of self-initiated activities and follow their collective path of playful exploration and questioning. It also constrains the actions and provides immediate feedback that are meant to highlight the relevant relations. In the study, we asked whether it fosters a deeper understanding of how driving and traffic relate, and how congestion might be alleviated.

As this is the first implementation, we began with the most open-ended version of the activity we could think of, and test what needed supports in later versions. The teacher provided the first two challenges (find yourself, make traffic jam), but then the students designed and orchestrated the simulations themselves. Conversations, while facilitated by the teacher, did not introduce new traffic or complexity concepts. This level of intervention reflects a relatively open-ended and minimally-guided version of discovery learning. We use this opportunity to examine discovery learning as it played out in a partSims design

The study shows only limited support for our version of discovery learning claims that by removing the teacher's direction and replacing it with constraints that come from the social and technological arenas, discovery learning could be facilitated.

In terms of the driving in the simulation, this conjecture is supported. We saw students adopting driving behaviors that were more conducive to smoothing traffic - reducing lane changes, keeping their individual speeds from changing too much - behaviors that resulted in a greater collective speed. These behaviors were not taught by the teacher or learning materials, but were discovered through interactions and conversations during the simulation runs and between them. The fact that more students complied with these strategies at the end shows their growing understanding of how each person impacts the collective through their interactions. Whether the students would then use these same behaviors in driving real cars, we don't have an answer. We had tried to test for that using a well-validated questionnaire about driving behaviors, but as described above, could not analyze the data. 
Different from the driving behaviors that support the original claim, the questionnaire results validate it only in part. Almost half the students did not express conceptual learning in their written questionnaires. What was learned is not uniform across students - different students learned different concepts regarding traffic. These results may or may not align with what was happening during the activities. While the students were noisily active during the simulation runs, and discussions were animated, involving many of the students - one cannot know what each student was experiencing. One of the central problems is a limited set of data sources. In the second round of this research, we are planning additional data sources, such as clinical interviews, which tend to elicit students' ideas better than written questionnaires and videotaping. Nevertheless, it is also important to note that this was the first implementation of the simulation that was done in a school. Given the germinal stage of development, one cannot expect as much as from a fully-fledged design effort. In noting what was not learned as well, we are redesigning the simulation to help notice certain features of traffic that were missed and additional aspects of the activities that encourage reflection during the activity.

Returning to Table 1 that presents our learning goals, we can compare them with our findings. With respect to understanding the three phases of traffic, the students came to understand this concept inaction but did not articulate the idea. In driving and designing experiments they shifted from heavy congested traffic to the coordinated phase (heavy but steady). Regarding phantom jams - long-term congestion resulting from a local fluctuation such as sudden braking - most of the students came very close to understanding it. We have seen this in explanations that related various local driving behaviors such as braking or cutting in to congestion. Backward propagation of traffic jams was not learned; nonetheless, we are not sure this is an important concept to learn, given that it is difficult to separate from other phenomena in traffic. Queuing at merges was not learned; however, this results from the roads in the simulation not including merging experiences. "Slower is faster", a counter-intuitive idea that lowering speeds and reducing interactions among vehicles would speed up traffic was learned by most of the students.

Mitigating effects on congestion were learned as well as seen in the explicit driving behaviors they adopted in the simulation to speed up traffic and their explanations of congestion following the intervention. Despite the activity's short duration and its initial stage of design, we have provided evidence that collaborative discovery learning is possible. Some surprising concepts were learned without direct instruction. The last two conceptions were probably learned uniquely from the learning situation, as most experienced adult drivers are unaware of these ideas. Nevertheless, only half of the students shifted in their grasp of at least one important concept regarding traffic, and even then - this is a piecemeal understanding that needs more integration with other concepts and consolidation. We are also encouraged by the wide spread of concepts learned - understanding the importance of headway (distance between cars) to free traffic flow, how car density, lane changes and cutting in change the flow from slow and steady to congested and the phenomenon of queuing.

Of course, this is a preliminary design study. Given its novelty as a topic of learning and as a learning design, we believe that it has shown rather positive results. However, this is only the first step in 
that direction. Based on the results of this study, the simulation, the activities and the data collection tools are being re-designed.

With respect to the simulation, the roads are being redesigned to include more experiences of merging, a topic that was not brought up by the students. In order to observe the distinct effects of various variables upon congestion, shorter roads will eliminate the need for using computer-controlled cars and trucks so that perhaps, the phenomenon of phantom jams can be simulated. The public visual display is changing to help focus on the main causal features in the system - accenting density and speed on one hand, and spurious actions such as cutting in and lane change, on the other hand. Additional metrics will be added to the simulation so that the three phases of traffic will become salient, such as number of stopped cars and a histogram of speeds.

Regarding the activities, worksheets are being devised to accompany the activity that include more cues as to the features of traffic and actions that can be noted. In these worksheets, the students can conduct individual work, such as explaining and designing activities, before collaborating on ideas. Minimal teacher facilitation of the more advanced concepts of traffic phenomena is also being designed to complement the discovery learning processes we have seen in the present study. Challenges and structural changes are being designed to support understandings that were less frequently reached, embedded in the constraints of the activity, rather than verbalized.

Our data collection tools were rudimentary and are now being developed and piloted, so that they address a wide range of concepts related to traffic and complex systems, as well as self-reported driving behaviors. In this first study, we could not videotape the lessons, as a result of local constraints. In the next round of research, the use of videotapes and screen capture will support a deeper understanding of the process of learning. In addition, the use of more advanced single-user car driving simulations that are normally used in research into driving will test the relationship between results that are seen through activities, questionnaires and interviews and actual driving.

Finally, research is planned to compare learning with the newer and better TrafficJams partSims with learning through more conventional means, using lectures, movies and worksheets.

\subsection{RQ2: Individual Action amidst Multiple Social Activities within a Constrained Responsive Learning Environment: The Design Framework}

Finally, we ask how TrafficJams might support this learning through the design principles, underscored in the framework. The results of this study are now discussed in terms of the proposed framework's five design principles.

Individual action was the starting point for the students' experiences with the participatory simulation. We have seen how the initial stage mainly involved students "finding their body" in the simulation and testing their possible actions. Some students were frustrated by limitations such as not being able to reverse or not understanding how to shift lanes. Students' articulations shifted back and forth between a focus on their own agent in the simulation to their local interactions, such as figuring out who was blocking their way. The same information was available to the students at the different stages of the 
simulation. However, at the beginning they attend only to the individual and local aspects, such as "People are colliding with me all the time!" and "Why did you pass me? ". Later in the activities, they come to include more global views such as traffic jams, or the smoothness of the traffic flow, while retaining a connection with individual action as in "The point is that the same behavior of keeping your distance both accelerates traffic and prevents accidents." Taking a developmental view to learning about complex systems that sees the earlier stages as nested within the later ones, and their complementary interactions seems to bear out in the enaction, supporting a sophisticated view of the system.

Social interactions complement individual action for participatory simulations successfully supporting a local-global view of systems. Without them, the activity would soon peter out. Designing for collaboration makes students' experiences observable, communicable and shared. Ideas for play and experimentation can emerge and gradually coordinate in this social arena. In the case of a partSim, these interactions are not only verbal but also as direct action within the virtual space: a car cannot move forward if there is another car standing in front without causing an accident. Thus, students mutually constrain each other's actions as members of a system in which they are all participating. This architecture invites several types of conversations and changes in the course of simulation activities, relating both to local interactions "Who's number one? You're blocking me." and global aspects of the traffic system impacting the individual "It's stuck. Because they decided that we're driving faster, we all got stuck.". These conversations that take place during each phase of the simulation runs were shown to fall into one of three patterns: calling out to each other during the activity, designing and converging on agreed-upon experiments and, discussing and interpreting the results of simulation runs. These exchanges arise naturally without external elicitation as they are part of the process of running the simulation several times. It is important to notice how the structural aspects of the design support the shifts in this instance of collaborative discovery learning - from local to local-global reasoning throughout the sequence of activities, and between these three types of conversations for each of the simulation runs. It is this character of co-dependence in the direct interactions within the simulation and the need to coordinate the group's efforts that makes the social aspect of collaborative discovery learning unique.

"Multiple activities" is a design principle that adds a degree of freedom. Its motivation was increasing the range of possibilities for discovery learning, by letting the students determine the type of activity, whether it involves solving problems, conducting inquiry, designing the system, tinkering or testing the limits of the system. We have found the students conducted several types of activities. At the start, when not directed, we could see them playing around and tinkering with the individual settings, trying to figure out what they can and cannot do. They first spiritedly moved about to get a sense of their bodies and learn their environment. In moving around, they noticed only local constraints not yet attending to the systems as a whole. The teacher's playful call in the ensuing part: "Let's make traffic jam" set the tone opening up the arena to the students' initiatives, invented games and strategies. As a group, they then tested the limits of the system by creating the biggest traffic jam they could: "we should drive as fast as possible and then there will be collisions and a traffic jam.”. When the teacher called for designing strategies to 
make traffic move faster, this set the activity as a problem-solving type. While solving problems, students conducted a more careful experimentation with driving behaviors. A number of students used this freedom to test the limits of the system by driving very fast through steady traffic. To conclude, we can see that students' choices of activity type changed over time across the different simulations, but also varied for a single run of the simulation. Indeed, a variety of activity types are evident in the combination of the teacher's more general challenges and students' choices of strategies to run each stage of the simulation activities. This choice of format allows for students' adaptation of the activity to their needs, whether tinkering to figure out the individual underlying rules or experimenting with speeds to determine the best course of action for collaborative driving. This adaptation enables the students' shift of attention from local to global features, supporting their learning of the traffic system as complex.

Describing the system as a constrained and responsive learning environment presents a design principle that on one hand provides feedback to actions, but also limits the possible actions. For example, limiting the students' driver controls to accelerating, decelerating and shifting lanes, actions that are more crucial to changing levels of congestion, was designed to help students focus on the traffic system. We did not include the option to reverse their motion, and they did not need to steer their wheel. Removing these features caused learning to drive in the simulation to be a much faster process, so that the students could then focus on the relationship between the enabled behaviors and the global features of traffic such as the average speed with respect to other simulation runs and its temporal trends within a single run. This is an example that shows our attempts at minimizing the information in the array of activities and visual displays of the system. By limiting actions and reducing details in the public displays the central concepts relating driving behaviors and traffic patterns are made more salient. The system was constrained to help focus on the main ideas that the learning process was designed for. For this more limited set of possible actions, the system is responsive. The simulation is dynamic, the state at each moment resulting from the previous state and participants' actions. In fact, the students are initially surprised when there is no response, such as when there is a car stuck in front of them. This responsiveness enables exposure to many local cause-andeffect instantiations, eventually supporting a mapping between behaviors and their local results, gradually increasing the angle of perspective to include global results as well. Thus, a small range of actions was offered to the students and the system responded to these actions in real time, supporting learning of some of the traffic concepts.

"Highlight target relations" is a design principle that helps select and design the feedback to actions. Within the TrafficJams simulation, some results were more prominent than others. In the bedlam that resulted when everybody first starts to move, we included red splatters of blood to signify traffic accidents. Highlighting these accidents was necessary to call attention to why they could not always advance their car, and what would happen if they did. Noticing interactions among the agents in a complex system is a crucial component in conceiving of it as complex; people do not easily notice these interactions, and so this process needs to be supported. Once this principle was established, the blood was removed from the simulation's representation. Being able to typify traffic as a system was another design goal. Students 
expressed their notions of the system's properties in a gradually decentering sequence of getting stuck, slowing down as a result of other drivers' decisions or everybody being in a jam. In order to help them quantify the latter "everybody being in a jam" a plot of the cars' average speed was introduced later on in the activity. This quantification and the possibility to compare the simulation runs helped them create an external objective criterion for their strategies' success.

Going back to the design for collaborative discovery learning, based on the findings of this study, this framework shows promising support. In action, students improved in their driving behaviors; in articulation, only about half the students showed the understanding of traffic that are behind these improved behaviors. Specific design principles were used to expand the range of possibilities for exploring the system, so that the students' autonomy asserts itself in leading the process of learning. Other design principles made these freedom-based choices productive by providing physical and social feedback to individual and collective actions, in ways that help students attend to the causal structure of the explored system. One cannot conclude based on this study alone as it is too preliminary. However, it does show promising signs to the viability of discovery learning with participatory simulations in such contexts.

\section{Conclusion}

This work had two aims. One aim was to make explicit the reasoning behind the design for discovery learning, so that it can be designed for other domains and contexts. Articulating the design is important as other instantiations of these principles are possible, not only participatory simulations. These guiding principles could support the process of designing new types learning environments or improving existing ones in more specific ways. The second aim was to heighten safety in driving and in a broader way create and educate for a culture of understanding-in-driving of how congested traffic works optimally, despite limited information. Central concepts about traffic are highly counter-intuitive and even paradoxical when comparing micro- and macro-levels. Future research will test whether learning these concepts in a deep way translates into actual driving behaviors, and whether these could benefit traffic flow. 


\section{References}

Aleven, V. A., \& Koedinger, K. R. (2002). An effective metacognitive strategy: Learning by doing and explaining with a computer-based Cognitive Tutor. Cognitive science, 26(2), 147-179.

Alfieri, L., Brooks, P. J., Aldrich, N. J., \& Tenenbaum, H. R. (2011). Does discovery-based instruction enhance learning? Journal of Educational Psychology, 103(1), 1-18.

Ares, N., Stroup, W. M., \& Schademan, A. R. (2009). The power of mediating artifacts in group-level development of mathematical discourses. Cognition and Instruction, 27(1), 1-24.

Bando, M., Hasebe, K., Nakayama, A., Shibata, A., \& Sugiyama, Y. (1995). Dynamical model of traffic congestion and numerical simulation. Physical Review E, 51, 1035.

Bar-Gera, H., \& Shinar, D. (2005). The tendency of drivers to pass other vehicles. Transportation Research Part F, 8, 429-439.

Bar-Yam, Y. (1997). Dynamics of complex systems. Reading, Mass.: Addison-Wesley, The Advanced Book Program.

Bruner, J. S. (1961). The act of discovery. Harvard Educational Review, 31, 21-32.

Brunstein, A., Betts, S., \& Anderson, J. R. (2009). Practice enables successful learning under minimal guidance. Journal of Educational Psychology, 101(4), 790.

Chi, M. T., Bassok, M., Lewis, M. W., Reimann, P., \& Glaser, R. (1989). Self-explanations: How students study and use examples in learning to solve problems. Cognitive Science, 13(2), 145-182.

Christidis, P., \& Rivas, J.N.I. (2012). Measuring road congestion. Joint Research Centre Institute for scientific and policy reports. European Commission.

Colella, V. (2000). Participatory simulations: Building collaborative understanding through immersive dynamic modeling. The Journal of the Learning Sciences, 9, 471-500.

Cookson, G. \& Pishue, B. (2017). INRIX Global Traffic Scorecard. INRIX Research Report, February, 2017.

Cruise, T., Wagner, P., \& Haicheng, Z. (Producers) \& Abrams, J.J. (Director). (2006). Mission Impossible III [Motion Picture]. USA: Paramount Pictures.

Csikszentmihalyi, M. (1996). Creativity: Flow and the Psychology of Discovery and Invention. Harper Perennial.

Dean Jr, D., \& Kuhn, D. (2007). Direct instruction vs. discovery: The long view. Science Education, 91(3), 384-397.

Enyedy, N., Danish, J., DeLiema, D., Saleh, A., Lee, C., Morris, N., \& Illum, R. (2017, January). Social Affordances of Mixed Reality Learning Environments: A case from the Science through Technology Enhanced Play project (STEP). In Proceedings of the 50th Hawaii International Conference on System Sciences.

Evans, L. (1996). Comment: The dominant role of driver behavior in traffic safety. American Journal of Public Health, 86, 784-786.

Falk, J., \& Storksdieck, M. (2005). Using the contextual model of learning to understand visitor learning from a science center exhibition. Science Education, 89(5), 744-778.

Fatality Analysis Reporting System (FARS) 2017. Retrieved March 8 ${ }^{\text {th }}$, 2017. http://wwwfars.nhtsa.dot.gov/Main/index.aspx

Gershenson, C. (2005). Self-organizing traffic lights. Complex Systems, 16(1), 29-53.

Gibson, E.J. (1988). Exploratory behavior in the development of perceiving, acting and the acquiring of knowledge. Annual Review of Psychology, 39, 1-41.

Hmelo-Silver, C. E., \& Pfeffer, M. G. (2004). Comparing expert and novice understanding of a complex system from the perspective of structures, behaviors, and functions. Cognitive Science, 28, $127-$ 138.

Jacobson, M. J. (2001). Problem solving, cognition, and complex systems: Differences between experts and novices. Complexity, 6(3), 41-49.

Johnson, D.W., \& Johnson, R.T. (2009). An Educational Psychology Success Story: Social Interdependence Theory and Cooperative Learning. Educational Researcher, 38, 365-379.

Kapur, M. (2008). Productive Failure. Cognition and Instruction, 26(3), 379-424

Karndacharuk, A., Wilson, D. J., \& Dunn, R. (2014). A review of the evolution of shared (street) space concepts in urban environments. Transport Reviews, 34(2), 190-220

Kerner, B. S., \& Konhäuser, P. (1993). Cluster effect in initially homogeneous traffic flow. Physical Review E, 48, 2335. 
Kerner, B.S. (2004). The physics of traffic: Empirical freeway pattern features, engineering applications and theory. Berlin: Springer.

Kirschner, P. A., Sweller, J., \& Clark, R. E. (2006). Why minimal guidance during instruction does not work: An analysis of the failure of constructivist, discovery, problem-based, experiential, and inquiry-based teaching. Educational Psychologist, 41(2), 75-86.

Klopfer, E., Yoon, S., \& Perry, J. (2005). Using palm technology in participatory simulations of complex systems: A new take on ubiquitous and accessible mobile computing. Journal of Science Education and Technology,14(3), 285-297.

Lee, H.S., \& Anderson, J.R. (2013). Student learning: What has instruction got to do with it? Annual Review of Psychology, 64, 445-469.

Lincoln, Y.S. \& Guba, E.G. (1985). Naturalistic Inquiry. Newbury Park, CA: Sage Publications.

Mayer, R. E. (2004). Should there be a three-strikes rule against pure discovery learning? American Psychologist, 59(1), 14-19.

Ministry of Education, Israel, Road Safety Branch (2017). Retrieved from http://cms.education.gov.il/EducationCMS/Units/Zahav/TochniyotLimudim/ March $8^{\text {th }}, 2017$.

Mzaviation (2011). SLR Canon Powershot SX30 IS Miniature Effect Test. Retrieved from https://www.youtube.com/watch?v=ii6tJVdln1o1.8.17.

Nagel, K. \& Schreckenberg, M. (1992). A cellular automaton model for freeway traffic. Journal Physique I, 2, 2221.

Perkins, D. (1999). The many faces of constructivism. Educational Leadership, 57(3), 6-11.

Petridou, E., \& Moustaki, M. (2000). Human factors in the causation of road traffic crashes. European Journal of Epidemiology, 16, 819-826.

Resnick, M. \& Wilensky, U. (1998). Diving into complexity: Developing probabilistic decentralized thinking through role-playing activities. The Journal of the Learning Sciences, 7, 153-172.

Rieber, L. P., Tzeng, S. C., \& Tribble, K. (2004). Discovery learning, representation, and explanation within a computer-based simulation: Finding the right mix. Learning and Instruction, 14(3), 307323.

Schmidt, R.A., (1975). A schema theory of discrete motor skill learning. Psychological Review, 82, 225260.

Sfard, A. (2008). Thinking as communicating. Cambridge, MA: Cambridge University Press.

Shinar, D., \& Compton, R. (2004). Aggressive driving: an observational study of driver, vehicle, and situational variables. Accident Analysis and Prevention, 36, 429-437.

Siegler, R. S. (2002). Microgenetic studies of self-explanation. Microdevelopment: Transition processes in development and learning, (Cambridge Studies in Cognitive and Perceptual Development), pp 3158. Cambridge, MA: Cambridge University Press

Sikron F, Baron-Epel O, Linn S. Development of a tool measuring 'selfish aggressive driving'. Transportation Research: Part F: Traffic Psychology and Behaviour, 11(1), 24-36.

Sikron, F., Baron-Epel, O., \& Linn, S. (2008). The voice of lay experts: Content analysis of traffic accident "talk-backs". Transportation Research Part F, 11, 24-36.

Silverfox1100 (2009). The phantom traffic jam - an explanation. Retrieved from https://www.youtube.com/watch? $\mathrm{v}=$ goVjVVaLe10\&feature=youtu.be 1.8.17

Stroup, W. M., \& Wilensky, U. (2014). On the embedded complementarity of agent-based and aggregate reasoning in students' developing understanding of dynamic systems. Technology, Knowledge and Learning, 19(1-2), 19-52.

Sugiyama, Y., Fukui, M., Kikuchi, M., et al. (2008). Traffic jams without bottlenecks - experimental evidence for the physical mechanism of the formation of a jam. New Journal of Physics, 10, 1-7.

The National Road Safety Authority (2008a). Road accidents data. The Research and Development Department. Retrieved from http://www.rsa.gov.il/news/Pages/maegmot2008.aspx / Retrieved 4.8.09.

Treiber, M. Helbing, D. (2001) Microsimulations of freeway traffic including control measures. Automatisierungstechnik, 49, 478-484.

Verschuur, W.L., Hurts, K., 2008. Modeling safe and unsafe driving behavior. Accident Analysis and Prevention, 40, 644-656.

Vicsek, T. (2002). Complexity: The bigger picture. Nature, 418(6894), 131-131.

von Hofsten, C. (1993). Prospective control: A basic aspect of action development. Human Development, $36,253-270$. 
Vygotsky, L.S. (1978). Mind in society. Cambridge, MA: Harvard University Press

Wagenaar, W.A., Reason, J.T., 1990. Types and tokens in road accident causation. Ergonomics, 33, 13651375.

Wilensky, U. (1997). NetLogo Traffic Basic model. http://ccl.northwestern.edu/netlogo/models/TrafficBasic. Center for Connected Learning and Computer-Based Modeling, Northwestern University, Evanston, IL.

Wilensky, U. (1999). NetLogo. http://ccl.northwestern.edu/netlogo/. Center for Connected Learning and Computer-Based Modeling, Northwestern University, Evanston, IL.

Wilensky, U., \& Abrahamson, D. (2006). Is a disease like a lottery?: Classroom networked technology that enables student reasoning about complexity. Paper presented at the annual meeting of the American Educational Research Association, San Francisco, CA.

Wilensky, U., \& Resnick, M. (1999). Thinking in Levels: A Dynamic Systems Perspective to Making Sense of the World. Journal of Science Education and Technology, 8(1), 3-19.

Wilensky, U., \& Stroup, W. (1999). Learning through participatory simulations: Network-based design for systems learning in classrooms. Proceedings of Computer Supported Collaborative Learning (CSCL'99). Stanford, CA, December 12 - 15. 
RUNNING HEAD: DISCOVERING PRINCIPLES OF TRAFFIC CONGESTION

\section{List of Figures}

Fig. 1 TrafficJams participatory simulation interface

Fig. 2 TrafficJams class simulation conducted in a computer lab. The simulation (left) sends and receives information from individual clients operated by the students (right)

Fig. 3 Descriptors of the four runs of the TrafficJams Simulation based on Logs $(\mathrm{N}=18)$ 
RUNNING HEAD. DISCOVERING PRINCIPLES OF TRAFFIC CONGESTION 
Table 1: Challenges in Conceptual Understanding of Complexity and Related Traffic Patterns, Aligned with Activities in the Simulation

\begin{tabular}{|c|c|c|}
\hline $\begin{array}{c}\text { Complexity } \\
\text { Concepts }\end{array}$ & Traffic Concepts & Activities in Simulation \\
\hline $\begin{array}{l}\text { Nonlinear } \\
\text { transitions in } \\
\text { systems, similar to } \\
\text { phase change in } \\
\text { matter }\end{array}$ & $\begin{array}{l}\text { Traffic phases: Traffic flow can be typified by three } \\
\text { phases (Three phase traffic theory; Kerner, 2004): free } \\
\text { flow, synchronized flow (heavy but steady), wide } \\
\text { moving jams (congestion). Beyond a critical vehicle } \\
\text { density, the state of flow changes from stable to } \\
\text { synchronized (breakdown phenomenon), or from } \\
\text { synchronized to unstable (pinch effect). }\end{array}$ & $\begin{array}{l}\text { Changing the number of robot } \\
\text { cars in the simulation to } \\
\text { experience and transition between } \\
\text { the phases. }\end{array}$ \\
\hline $\begin{array}{l}\text { Distributed control; } \\
\text { nonlinear effects }\end{array}$ & $\begin{array}{l}\text { Phantom jams: Traffic congestion can result from } \\
\text { amplification of local fluctuations (e.g. one driver } \\
\text { breaking heavily or cutting into traffic) in heavy traffic } \\
\text { and not necessarily from a bottleneck, such as accidents } \\
\text { or construction (Nagel \& Schreckenberg, 1992; Bando } \\
\text { et all, 1995). Dissipation of such a disturbance takes } \\
\text { time. }\end{array}$ & $\begin{array}{l}\text { Driving above a critical vehicle } \\
\text { density, students experience the } \\
\text { propagation is explored. } \\
\text { Participants can explore the effect } \\
\text { of braking or cutting into traffic. }\end{array}$ \\
\hline $\begin{array}{l}\text { Micro and macro } \\
\text { level behaviors are } \\
\text { distinct }\end{array}$ & $\begin{array}{l}\text { Backward propagation of traffic jams: Traffic waves } \\
\text { usually travel downstream counter to the vehicles' } \\
\text { direction of travel (Kerner \& Kornhauser, 1993; } \\
\text { Nagatani, 2002; Sugiyami et al., 2008). }\end{array}$ & Same as above. \\
\hline $\begin{array}{l}\text { Distributed control; } \\
\text { "butterfly" effect }\end{array}$ & $\begin{array}{l}\text { Queuing at merges: Merging traffic propagates a } \\
\text { system-wide congestion that causes queuing as a result } \\
\text { of incoming fast cars distance until moving lanes after } \\
\text { the merge (Daganzo, 2002). }\end{array}$ & $\begin{array}{l}\text { Merging traffic is introduced in } \\
\text { the simulation on the fly and its } \\
\text { effects are explored. }\end{array}$ \\
\hline $\begin{array}{l}\text { Micro and macro } \\
\text { level behaviors are } \\
\text { distinct }\end{array}$ & $\begin{array}{l}\text { Slower is faster: In congested traffic, imposing and } \\
\text { lowering limits to speed causes reduction in } \\
\text { interactions among the cars and increases their speed } \\
\text { (Treiber, \& Helbing, 2001) }\end{array}$ & $\begin{array}{l}\text { Participants can test the effect of } \\
\text { their driving speed on the traffic - } \\
\text { manually or automatically (by the } \\
\text { host simulation) }\end{array}$ \\
\hline $\begin{array}{l}\text { Designing for } \\
\text { complexity }\end{array}$ & $\begin{array}{l}\text { Mitigating effects: Knowing how traffic waves are } \\
\text { created, drivers can reduce their effects by increasing } \\
\text { vehicle headways and reducing the use of the brakes. }\end{array}$ & $\begin{array}{l}\text { Participants develop strategies for } \\
\text { mitigating congestion and test } \\
\text { them out, e.g.: speed control, } \\
\text { sufficient headway, less traffic- } \\
\text { slowing forms of merging, and car } \\
\text { passing. }\end{array}$ \\
\hline
\end{tabular}


Table 2: Descriptors of the Four Runs of the TrafficJams Simulation based on Logs (N=18)

\begin{tabular}{llcccc}
\hline & Simulation Run Number & 1 & 2 & 3 & 4 \\
\hline $\begin{array}{l}\text { Driving } \\
\text { Behaviors }\end{array}$ & $\begin{array}{l}\text { Average number of speed } \\
\text { changes per person per tick }\end{array}$ & .224 & .203 & .379 & 0.0408 \\
& $\begin{array}{l}\text { Average number of lane } \\
\text { changes per person per tick }\end{array}$ & .054 & .471 & .639 & .492 \\
& Duration of run (ticks $\left.{ }^{1}\right)$ & 551 & 223 & 137 & 139 \\
\hline Traffic & Average speed (patches ${ }^{2} /$ tick $\left.^{1}\right)$ & $44(60)$ & $14(31)$ & $46(80)$ & $66(34)$ \\
& & $\min =0$ & $\min =0$ & $\min =0$ & $\min =0$ \\
& & $\max =560$ & $\max =480$ & $\max =500$ & $\max =250$ \\
& Average number of laps & $8.63(1.89)$ & $.444(.615)$ & $1.06(.800)$ & $4.72(.461)$ \\
& completed & $\min =5$ & $\min =0$ & $\min =0$ & $\min =4$ \\
& & $\max =12$ & $\max =2$ & $\max =2$ & $\max =5$ \\
\hline
\end{tabular}

${ }^{1}$ A tick is a simulation time unit, and includes one round through the main procedure. In terms of clock time, it can vary based on the computation made.

${ }^{2} \mathrm{~A}$ patch is a space or distance unit in NetLogo. 
Table 3: Shifts in Reasoning about Traffic from Pretest to Posttest

\begin{tabular}{|c|c|c|}
\hline Dimension & Pretest & Posttest \\
\hline $\begin{array}{l}\text { Centralized } \rightarrow \\
\text { Decentralized }\end{array}$ & $\begin{array}{l}\text { [The source of the traffic jam?] "An } \\
\text { accident" }\end{array}$ & $\begin{array}{l}\text { "Because the cars slow down and } \\
\text { speed up a greater density is formed. } \\
\text { And also because of the congestion." }\end{array}$ \\
\hline $\begin{array}{l}\text { Single } \rightarrow \\
\text { Multiple Causes }\end{array}$ & $\begin{array}{l}\text { "A flow of cars in a certain direction } \\
\text { such as travelers returning south from } \\
\text { the north." }\end{array}$ & $\begin{array}{l}\text { "The main reason is having a lot of } \\
\text { cars flowing in a certain direction, in } \\
\text { addition to cars trying to pass each } \\
\text { other, which causes a lot of braking." }\end{array}$ \\
\hline $\begin{array}{l}\text { Single cars } \rightarrow \text { Car } \\
\text { speed distribution as } \\
\text { generating jams }\end{array}$ & $\begin{array}{l}\text { "I think the traffic jams form because } \\
\text { of congestion on the roads and the } \\
\text { sudden stops of cars, that forms the } \\
\text { congestion." }\end{array}$ & $\begin{array}{l}\text { "I think the traffic jam forms because } \\
\text { there aren't enough lanes, and every } \\
\text { driver drives at a different speed, so } \\
\text { that the slower ones slow the rest } \\
\text { down." }\end{array}$ \\
\hline $\begin{array}{l}\text { Top-down } \rightarrow \text { Bottom- } \\
\text { up reasoning }\end{array}$ & $\begin{array}{l}\text { "I think the jam is caused by merging } \\
\text { a number of lanes into a fewer } \\
\text { number of lanes, in addition to it } \\
\text { being a time when lots of cars are on } \\
\text { the road". }\end{array}$ & $\begin{array}{l}\text { "Cars slow down and speed up } \\
\text { during a traffic jam. I think this } \\
\text { happens because not all the drivers } \\
\text { drive at the same speed and that } \\
\text { causes everybody to slow down, } \\
\text { which causes the traffic jam." }\end{array}$ \\
\hline $\begin{array}{l}\text { Non-mechanistic } \rightarrow \\
\text { Mechanistic reasoning }\end{array}$ & & $\begin{array}{l}\text { "I think the jam formed because } \\
\text { people didn't keep enough distance } \\
\text { between them, that's why they had to } \\
\text { stop and this caused traffic }\end{array}$ \\
\hline & $\begin{array}{l}\text { "In the movie we saw a traffic jam on } \\
\text { a highway in Ashdod." }\end{array}$ & $\begin{array}{l}\text { congestion." } \\
\text { "As a result of incorrect road } \\
\text { behavior, the pushing, having each } \\
\text { driver want to be first, beyond the } \\
\text { basic reasonable reason of congestion } \\
\text { of traffic in a particular direction." }\end{array}$ \\
\hline
\end{tabular}


Table 4: Shifts in Reasoning about Traffic (Frequency out of $N=16$ ).

\begin{tabular}{lccc}
\hline Dimension & Improvement & Regression & Same \\
\hline Overall & 9 & 2 & 5 \\
\hline Centralized $\rightarrow$ Decentralized & 4 & 0 & 12 \\
Single $\rightarrow$ Multiple Causes & 3 & 1 & 12 \\
Single cars $\rightarrow$ Car speed distribution as & 4 & 0 & 13 \\
generating jams & 2 & 0 & 14 \\
Top-down $\rightarrow$ Bottom-up reasoning & 2 & 2 & 11 \\
Non-mechanistic $\rightarrow$ Mechanistic reasoning & & & \\
\hline
\end{tabular}




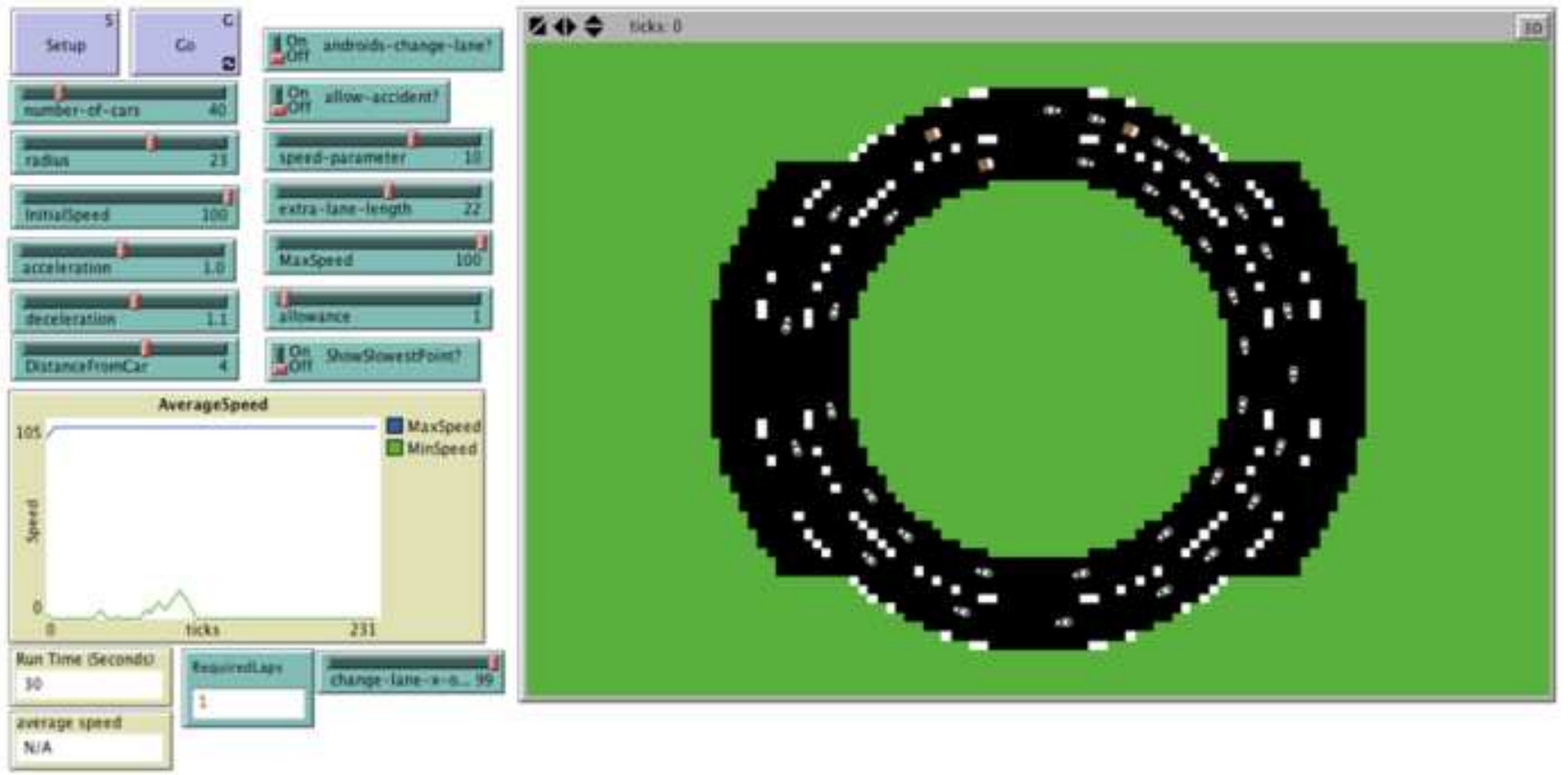



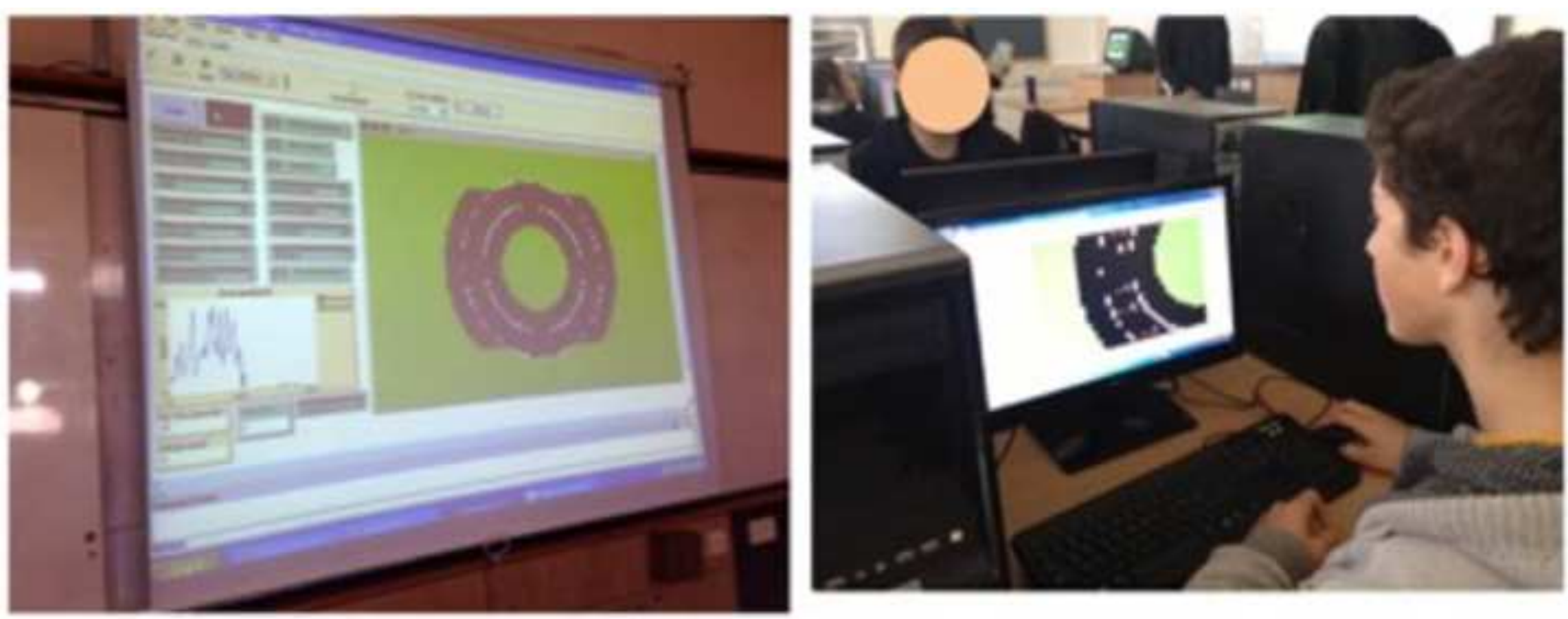


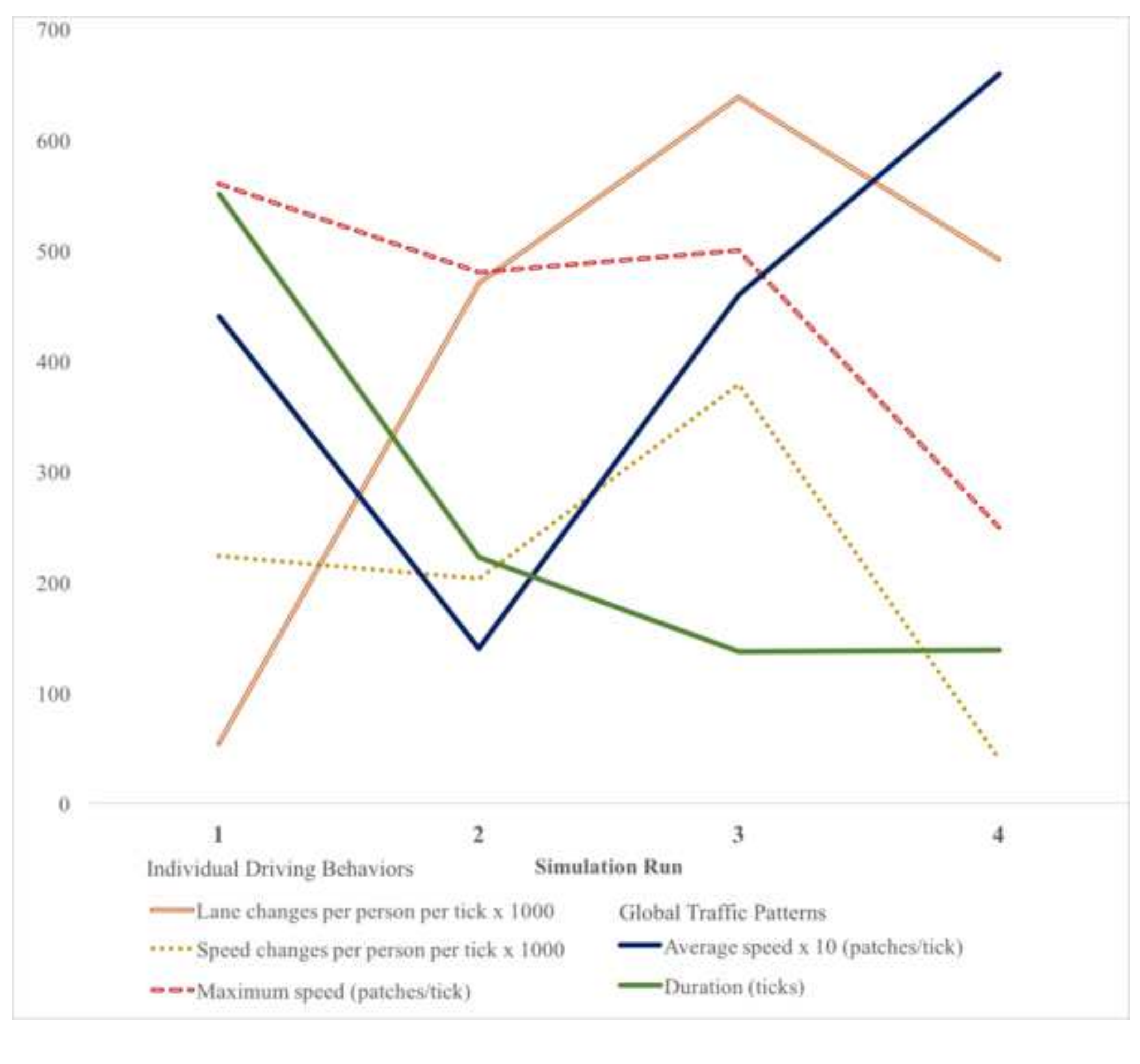

.
(1)
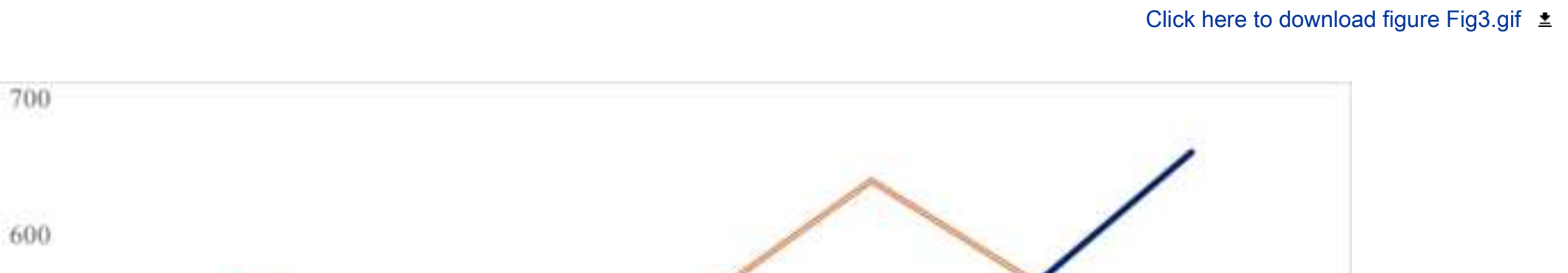